\title{
The Most Common Sports Injuries among Aerobics Practitioners in Jordan 2017
}

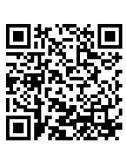

\author{
Majed F Mujalli1*, Alaa Kh Abu Aloyoun²*, Marwan Ghazzawi ${ }^{3}$ \\ ${ }^{1}$ Sport Medicine and Remedial Gymnastic, Amman, Jordan
}

${ }^{2} \mathrm{PhD}$ in physical education, Amman, Jordan

${ }^{3}$ Master Degree in physical education, Amman, Jordan

Submission: February 05, 2018; Published: February 26, 2018

*Corresponding author: Majed F Mujalli, Sport Medicine and Remedial Gymnastic, Amman, Jordan, Tel: 00962795540201;

Email: dr.majed_mujalli@hotmail.com

Alaa Kh Abu Aloyoun, PhD in physical education, Amman, Jordan, Tel: 00962797366644; Email: aboaloyoun.alaa@gmail.com

\begin{abstract}
This study aimed to identify the most common sports injuries among practitioners of aerobics in Jordan, and to identify areas of the most prone to injury and their causes. The randomly selected sample $(n=350)$ consisted of females practitioners of aerobics at the fitness centers in Amman-Jordan, where (180) participants were having injuries. The descriptive approach was used and Sports Injuries Checklist was distributed. Results showed that the body positions most prone to injury was the shoulder joint $18.6 \%$, and the most frequently occurring type of injuries was muscles rupture $24.2 \%$, and that the lack of good warm-up was the most common cause of sports injuries $22.2 \%$. The researchers recommend good pre-exercise warm-up, and avoid overtraining.

Keywords: Sports injuries; Aerobics
\end{abstract}

\section{Introduction}

Generally, the physical exercises form the core element in the athletic training process that should be carefully managed because they link the training components with the training outcomes. Practically, the physical exercises a set of bodily positions and movements aiming at achieving body fitness, building, improve health and wellness and develop one's overall kinematic capabilities up to highest possible level of functional and athletic performance by applying the scientific bases of kinematics [1-5]. Aerobics are the base of all other exercises because one can continue perform them for relatively a longer time, during which important physiological adaptations may occur to the human body, including improve functionality of the heart, increase efficiency of blood circulation and the respiratory system, and generally improve coordination between different (motor, sensory, auditory and temporal) control centers in the brain [6,7].

Recently, the aerobics exercises attracted much of the interest of people of different ages as they increase body flexibility, improve the functionality of the cardiovascular system by supplying energy during the constant body activity. On the other hand, aerobic exercises have become a priori for patients with chronic diseases like heart, diabetes, LBP diseases [8]. The fitness exercises, in general, and aerobics in particular, reduce effects of aging though prevention of heart and blood circulation diseases in addition to sustaining the musculoskeletal system and maintain memory. Research shows that the aerobics improves vitality in work as if one twenty years younger than real age, and as commonly noticed those practicing sports regularly seem younger than they are, and less probable to have heart diseases. Many studies found that practicing exercises regularly even at age of sixty yield positive effects in terms of wellness and living longer [9-13].
As other sports, the practice of aerobics may cause different injuries to practitioners in various positions of the body. The sport injuries occur during practicing a physical activity whether for recreation, training or competitions. Hence, the interest in sports injuries cases, treatment and prevention is primarily for evading their occurrence or at least alleviating their effects $[14,15]$.

\section{Statement of the Problem \& Significance}

This study addresses a population of the Jordanian community that seeks to improve health condition and body shape. Among other sports types, the aerobics attracts the interest of many sports practitioners due to its positive effects on the body health and functionality of body systems. This kind of sports is typically preferred to get rid of obesity or alleviate bone attrition pain. As participants in this study practice aerobics for medical reasons, the injuries surveyed among participants would seem inappropriate to the major reason for which physical activities are generally practiced; particularly the aerobics i.e. maintain body health and wellness.

The importance of the present study stems from the fact that the prevalence of the sports injuries among participants in this study would inhibit others to get involved in physical activities for maintaining their health in order to avoid the related injuries. Therefore, this study screened the various injuries associated with practicing the aerobics in terms of causes and position affected towards reducing the sports injuries as indicated by Mujalli [16]. 


\section{Objectives of the Study}

The study aims at identifying:

a) Sports injuries most common among aerobics practitioners in Jordan.

b) Body positions most prone to injuries among aerobics practitioners in Jordan.

c) Causes of the sports injuries among aerobics practitioners in Jordan.

\section{Study Questions}

a) What sports injuries are most common among aerobics practitioners in Jordan?

b) What are the body positions most prone to injuries among aerobics practitioners in Jordan?

c) What causes sports injuries among aerobics practitioners in Jordan?

\section{Study Procedures}

Methods: The descriptive approach was used due to appropriateness to the study goals.

Population: Aerobics female practitioners attending the fitness centers in Amman-Jordan.

Participants: Participants were female practitioners of the aerobics recruited from fitness centers in Amman during the period from September 20 to November 01, 2016 to participate in this study. The sample consisted of (350) aerobics practitioners who responded to the Sports Injuries Checklist. Out of 350, 180 aerobics practitioners (51.4\%) had injuries.

Instrumentation: To collect data, the authors used the Sports Injuries Checklist [17] Schedule 1.

Validity \& Reliability: The instrument validity was verified by the related studies used it with results confirms its validity to measure the purpose it intends to measure. To test for reliability, Pearson correlation and Cronbach alpha for internal consistency were tested (97\%).

Statistical Treatment: The statistical program SPSS was used to find out frequencies and percentages.

\section{Results}

Table 1 shows that mean age of female practitioners of aerobics at the fitness centers was (46.23; $S D=7.12)$, mean weight was $(68.49 \mathrm{Kg}$; $\mathrm{SD}=8.66)$, and mean tall $(164.78 \mathrm{~cm} ; \mathrm{SD}=9.35)$. Table 2 shows that muscle tear was the injury most frequently reported by aerobics practitioners $(24.2 \%)$, followed by muscle contusion $(15.7 \%)$ and in the third place was sprain $(10.8 \%)$. However, injury least frequently reported by aerobics practitioners at the fitness centers was "other injuries" (untargeted by this study) (1.3\%). The authors argue that the result that muscle tears were the injury most common among the aerobics practitioners would be due to lack of good warm-up, since lacking good warm-up is considered a direct and main factor in muscle tears as the muscle fibers are not ready yet for contraction relation so that they might be torn as shown by Table 3 that the most commonly reported reason for injuries is lack of good warm-up. As for muscle contusion they mostly result from collide of body parts with the earth during practice different skills or movements; i.e. poor technique that frequently reported as one of the major causes of injury (Table 3). Sprains, on the other hand, would be associated with the first three causes reported in Table 3, namely lack of good warm-up, overtraining, and poor technique. Table 4 shows that the body part most prone to sprain injury was the shoulder joint and ankle and this result is consistent with Mujalli [18], Mujalli and others [19].
Table 4 shows that among the body parts most commonly have injuries as a result of practicing aerobics at the fitness centers shoulder joints were ranked top (18.6\%), followed by thigh (9.8\%), and the ankle $(7.8 \%)$, whereas the body part least prone to injury by aerobics practitioners at the fitness centers were the abdomen, Lumbar vertebrae, Lumbar vertebrae, Posterior cruciate ligament, and Lateral collateral ligament $(0.3)$ for each.

The authors would explain the result that shoulder joint and ankle were the body parts most prone to injuries due to overload on such body parts during practicing the aerobics as clearly shown by Table 3 where the overtraining was ranked as the second cause for injuries. The shoulder joint and ankle are two important parts of the body that play a significant role in the kinematic performance of the aerobics. In general this result was in agreement with Abu Aloyoun [20] and Mujalli [18]. Table 3 shows that the causes for sports injuries most frequently reported by aerobics practitioners at the fitness centers were "lack of good warm-up" in the first rank (22.2\%), followed by "overtraining" (13.15), and lastly "poor technique" (7.8\%).

Table 1: Means and Standard Deviations of subject responses by variables of age, tall, weight of female practitioners of aerobics at the fitness centers.

\begin{tabular}{|c|c|c|}
\hline Variable & M & SD \\
\hline Age $(\mathrm{yrs})$ & 46.23 & 7.12 \\
\hline Weight $(\mathrm{Kg})$ & 68.49 & 8.66 \\
\hline Tall $(\mathrm{cm})$ & 164.78 & 9.35 \\
\hline
\end{tabular}

Table 2: Frequencies and percentages of sports injuries types among female practitioners of aerobics at the fitness centers.

\begin{tabular}{|c|c|c|}
\hline Percentages\% & Frequencies F & Injury Type \\
\hline 5.6 & 17 & Fractures \\
\hline 8.8 & 27 & Ruptured Tendon \\
\hline 24.2 & 74 & Muscle Tear \\
\hline 8.2 & 25 & Ligament Sprain \\
\hline 5.6 & 17 & Dislocation \\
\hline 4.2 & 13 & Bone Bruise \\
\hline 15.7 & 48 & Muscle Contusion \\
\hline 3.3 & 10 & Nerve Contusions \\
\hline 3.3 & 10 & Cuts \& Abrasions \\
\hline 9.2 & 28 & Contraction \\
\hline 10.8 & 33 & Sprain \\
\hline 1.3 & 4 & Other Injuries \\
\hline 100.0 & 306 & Total \\
\hline
\end{tabular}

The authors would attribute this result to insufficient knowledge held by coaches to the basics, rules and importance of warm-up, and even lack of knowledge about good training practices by both practitioners and coaches. This conclusion is supported by the second cause i.e. "overtraining". Poor preparation and technique would be linked to lack of experience to practice the aerobics sports, the result that agrees with Mujalli, Al-Saleh [14]; Mujalli et al. [19]; Al-Shatnawi [21]; Mujalli, Gzawi [22]. 


\section{Journal of Physical Fitness, Medicine \& Treatment in Sports}

Table 3: Frequencies and percentages of causes of sports injuries among the female practitioners of aerobics at the fitness centers.

\begin{tabular}{|c|c|c|c|}
\hline No. & Cause & Frequencies $\mathrm{F}$ & Percentages\% \\
\hline 1 & Lack of good warming-up & 68 & 22.2 \\
\hline 2 & Overtraining & 40 & 13.1 \\
\hline 3 & Malpractice by practitioners (inattention, hasty, violation game rules) & 20 & 6.5 \\
\hline 4 & Court inappropriate for training & 22 & 7.2 \\
\hline 5 & Poor technique & 24 & 7.8 \\
\hline 6 & Keep training despite injury & 16 & 5.2 \\
\hline 7 & No stop of training at the time of injury & 5 & 1.6 \\
\hline 8 & Inappropriate athletic outfits & 19 & 6.2 \\
\hline 9 & Unavailability of certain training program & 5 & 1.6 \\
\hline 10 & Poor quality of the sports devices used & 6 & 2.0 \\
\hline 11 & Insufficient guidance by the trainer & 5 & 1.6 \\
\hline 12 & Poor physical conditions (light, temperature, humidity) & 7 & 2.3 \\
\hline 13 & The exercises badly fit with the muscles employed in the game & 7 & 2.3 \\
\hline 14 & Lack of supervision by the trainer (general physiological features) & 0 & 0.0 \\
\hline 15 & The trainer is inadequately qualified & 2 & 0.7 \\
\hline 16 & Player allowed return to training before recovery & 7 & 2.3 \\
\hline 17 & Lack of sufficient equipment and instruments for training & 7 & 2.3 \\
\hline 18 & Lack use of athletic rehabilitation facilities (Sauna, massage,...) & 14 & 4.6 \\
\hline 19 & Poor timing for training and games & 0 & 0.0 \\
\hline 20 & Missing periodic check-ups & 7 & 2.3 \\
\hline 21 & Malnutrition & 3 & 1.0 \\
\hline 22 & Disregard individual differences among players & 7 & 2.7 \\
\hline 23 & Poor psychological readiness & 5 & 1.6 \\
\hline 24 & $\begin{array}{l}\text { Inadequate knowledge about sports injuries, causes and prevention } \\
\text { methods }\end{array}$ & 7 & 2.3 \\
\hline 25 & Choosing improper sports type & 0 & 0.0 \\
\hline 26 & Disregard progressive increase of training load & & 0.0 \\
\hline 27 & Dopes Intake & & 0.0 \\
\hline 28 & Medical equipment and aids used (wheelchair, ear protectors, belts,..) & 0 & 0.0 \\
\hline 29 & Inadequate knowledge by player about ability level to exercise & 3 & 1.0 \\
\hline \multicolumn{2}{|r|}{ Total } & 306 & 100.0 \\
\hline
\end{tabular}

Table 4: Frequencies and percentages of positions of sports injuries among female practitioners of aerobics at the fitness centers.

\begin{tabular}{|c|c|c|}
\hline Percentages\% & Frequencies F & Injury Position \\
\hline 5.2 & 16 & Head Injuries \\
\hline 6.5 & 20 & Neck Injuries \\
\hline 18.6 & 57 & Shoulder Joint \\
\hline 1.6 & 5 & Clavicle \\
\hline 0.7 & 2 & upper arm \\
\hline 6.5 & 20 & Elbow joint forearm \\
\hline 5.6 & 17 & wrist joint \\
\hline 5.9 & 18 & Phalanx \\
\hline 6.5 & 20 & Sternum \\
\hline .00 & 0 & Ribs \\
\hline 3.6 & 11 & abdomen \\
\hline
\end{tabular}




\begin{tabular}{|c|c|c|}
\hline 2.3 & 7 & Cervical vertebrae \\
\hline 0.3 & 1 & Thoracic vertebrae \\
\hline 1.0 & 3 & Lumbar vertebrae \\
\hline 0.3 & 1 & Sacrum \\
\hline 0.0 & 0 & Pelvis \\
\hline 0.0 & 0 & hip \\
\hline 2.3 & 7 & thigh \\
\hline 9.8 & 30 & knee joint \\
\hline 3.6 & 11 & Posterior cruciate ligament \\
\hline 0.0 & 0 & Medial collateral ligament \\
\hline 0.3 & 1 & Lateral collateral ligament \\
\hline 0.0 & 0 & Leg \\
\hline 0.3 & 1 & Ankle \\
\hline 6.9 & 21 & medial malleolus \\
\hline 7.8 & 24 & lateral malleolus \\
\hline 2.6 & 8 & phalanges of the foot \\
\hline 0.0 & 0 & Total \\
\hline 1.3 & 4 & 306 \\
\hline
\end{tabular}

\section{Conclusion}

In light of the results from the current study, the following conclusions were drawn out

a) The sports injuries most commonly reported by the aerobics practitioners at fitness centers in Amman-Jordan were muscle tears, muscle contusions, and sprains.

b) The body positions most prone to sports injuries among aerobics practitioners were the shoulder joint, thigh and ankle.

c) The causes most reported by aerobics practitioners were lack of good warm-up, and overtraining [23-27].

\section{Recommendations}

In light of the earlier conclusions, the authors recommend the following:

a) Greater attention should be given to warming-up by aerobics practitioners to avoid injuries

b) Specialist trainers should focus on the theoretical aspects of injuries in terms of causes, prevention methods to reduce injuries among aerobics practitioners.

\section{References}

1. Abu Aloyoun Alaa (2016) Sports injuries Most Common among Karate Players in Jordan, $11^{\text {th }}$ Scientific Conference at the Faculty of Physical Education, University of Jordan. Integrity in Athletic Sciences, Egypt.

2. Al Ajmi Mohammad (2006) Psychological Factors Associated with Injuries in Individual and Group Activities, Faculty of Physical Education, Zaqaziq University, Egypt.

3. Albert C Hergenroder (2001) Prevention of Sports Injuries College of Medicine. Houston, Texas Pediatries 101(6): 1057-1063.

4. Al Shatnawi Mutasim (2002) Analytical Study of Sports injuries among team players in Mu'tah University. Assuit Journal, Egypt.

5. American Academy of Pediatrics (2015) Sports Injury Prevention Tip Sheet.
6. Douglas H Richie Jr, Steven F Kelso, Patricia A Bellucci (2016) Aerobic Dance Injuries: A Retrospective Study of Instructors and Participants. Phys Sportsmed 13(2): 130-140.

7. Koplan JP, Siscovick DS, Goldbaum GM (1985) The risks of exercise: a public health view of injuries and hazards. Public Health Rep 100(2): 189-195.

8. Lee A, June I, Thomas A (1988) Prevalence and types of injuries in aerobic dancers. Am J Sports Med 16(4): 403-407.

9. Mujalli Majed, Al Saleh Majed (2005) Analytical Study of Sports Injuries Causes among National Elite Team Players by the Sports Seasons in Jordan, Master Thesis, University of Jordan, Asia.

10. Mujalli Majed, Atiyat Khaled (2004) Analytical Study of Sports Injuries among Fencing Competitors in Jordan, Journal of Physical Education Research, Faculty of Physical Education for Male Students, Zaqaziq University, Egypt.

11. Mujalli Majed, Ghzawi Marwan (2009) Sports Injuries Common among Gymnasium Athletes in Jordan, $6^{\text {th }}$ Scientific Athletic Conference, Faculty of Physical Education, University of Jordan, Asia.

12. Mujalli Majed, Zghailat Muhanad, Braizat Suhaib (2012) Common Sports injuries among Karate Players in Jordan. Al Najah University Research "Humanistic Sciences", Egypt.

13. Mujalli Majed (2007) Sports Injuries among Basket Players in Jordan, $1^{\text {st }}$ Scientific Conference, Association of Faculties, Departments and Institutes of Physical Education in the Arab World, Egypt.

14. Mujalli M, Zakarneh M, Abu Aloyoun A (2016) The Common Athletic Injuries among Physical Activities Practitioners in the Physical Fitness Centers in Jordan (comparative Study). Asian Social Science 12(5): p. 24.

15. Pescatello LS (2014) Guidelines for exercise testing and prescription $\left(9^{\text {th }}\right.$ edn). American college of sports medicine. Philadelphia 58(3): 328.

16. JP Koplan, DS Siscovick, GM Goldbaum (1985) The risks of exercise: a public health view of injuries and hazards. Public Health Rep 100(2): PMC1424726. 
17. Potter H (1996) Lower limb injuries in aerobics participants in Western Australia: An incidence study. Australian Journal of Physiotherapy 42(2): 111-119.

18. Renstrome P (2003) Clinical Practice of Sports injury prevention and care.

19. Richard Hofstetter C, Melbourne F Hovell, Carol Macera, James F Sallis, Vivien Spry, et al. (2013) Illness, Injury, and Correlates of Aerobic Exercise and Walking: A Community Study. Research Quarterly for Exercise and Sport 62(1): 1-9.

20. Rooks DS, Silverman CB, Kantrowitz FG (2002) The effects of progressive strength training and aerobic exercise on muscle strength and cardiovascular fitness in women with fibromyalgia: A pilot study. Arthritis \& Rheumatism 47(1): 22-28.

21. Rosa BB (2014) Epidemiology of sport injuries on collegiate athletes at single center. Injury epidemiology a Springer open journal 22(6): 321-324.
22. Rushdi Mohammad Adel (2003) Scientific Research \& Physiology of Athlete Injuries, Al-Maaref for Printing \& Publishing, Alexandria, Egypt.

23. Tawfiq Faraj Abdulhameed (2004) Chemistry of Muscle Injuries and Bodiloy Fatigue for Athletes. Sports Biology Encyclopedia, (1 ${ }^{\text {st }}$ edn) "AlWafaLedina" Printing \& Publishing House, Egypt.

24. Twomey DM (2014) Ground condition as a risk factor in sports injury aetiology studies: the level of concordance between objective and subjective measures. Injury epidemiology a Springer open journal 1(1): 27.

25. Walker N, Barrow M (2013) The psychology of sport injury and rehabilitation. New York, USA.

26. Weisenthal BM (2014) Injury Rate and Patterns Among Cross Fit Athletes. Orthopedic journal of sport medicine 2(4): 2325967114531177.

27. Wong Pand, Mong Y (2005) Soccer Injury in the Lower extremities. British journal of sport medicine 39(8): 473-482.

\section{Your next submission with Juniper Publishers will reach you the below assets}

- Quality Editorial service

- Swift Peer Review

- Reprints availability

- E-prints Service

- Manuscript Podcast for convenient understanding

- Global attainment for your research

- Manuscript accessibility in different formats

( Pdf, E-pub, Full Text, Audio)

- Unceasing customer service

Track the below URL for one-step submission https://juniperpublishers.com/online-submission.php 